\title{
BMJ Open Clinical outcomes in 995 unselected real-world patients treated with an ultrathin biodegradable polymer-coated sirolimus-eluting stent: 12-month results from the FLEX Registry
}

Pedro A Lemos, ${ }^{1}$ Prakash Chandwani, ${ }^{2}$ Sudheer Saxena, ${ }^{3}$ Padma Kumar Ramachandran, ${ }^{4}$ Atul Abhyankar, ${ }^{5}$ Carlos M Campos, ${ }^{1}$ Julio Flavio Marchini, ${ }^{1}$ Micheli Zanotti Galon, ${ }^{1}$ Puneet Verma, ${ }^{6}$ Manjinder Singh Sandhu, ${ }^{7}$ Nikhil Parikh, ${ }^{8}$ Ashok Bhupali, ${ }^{9}$ Sharad Jain, ${ }^{10}$ Jayesh Prajapati ${ }^{10}$

To cite: Lemos PA,

Chandwani P, Saxena S, et al. Clinical outcomes in 995 unselected real-world patients treated with an ultrathin biodegradable polymercoated sirolimus-eluting stent: 12-month results from the FLEX Registry. BMJ Open 2016;6:e010028.

doi:10.1136/bmjopen-2015010028

- Prepublication history for this paper is available online. To view these files please visit the journal online (http://dx.doi.org/10.1136/ bmjopen-2015-010028)

Received 25 September 2015 Revised 8 January 2016 Accepted 18 January 2016

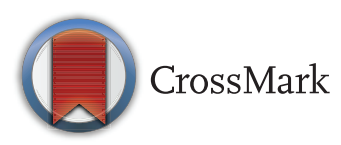

For numbered affiliations see end of article.

Correspondence to Dr Pedro A Lemos: pedro.lemos@incor.usp.br

\section{ABSTRACT}

Objectives: To evaluate, in the FLEX Registry, clinical outcomes of an ultrathin $(60 \mu \mathrm{m})$ biodegradable polymer-coated Supraflex sirolimus-eluting stent (SES) for the treatment of coronary artery disease.

Additionally, to determine the vascular response to the Supraflex SES through optical coherence tomography (OCT) analysis.

Setting: Multicentre, single-arm, all-comers, observational registry of patients who were treated with the Supraflex SES, between July 2013 and May 2014, at nine different centres in India.

Participants: 995 patients (1242 lesions) who were treated with the Supraflex SES, between July 2013 and May 2014, at nine different centres in India. A total of 47 participants underwent OCT analysis at 6 months' follow-up.

Interventions: Percutaneous coronary intervention with Supraflex SES,

Primary and secondary outcome measures: The primary endpoint - the rate of major adverse cardiac events (defined as a composite of cardiac death, myocardial infarction (MI), target lesion revascularisation (TLR)) - was analysed during 12 months.

Results: At 12 months, the primary endpoint occurred in $36(3.7 \%)$ of 980 patients, consisting of $18(1.8 \%)$ cardiac deaths, $16(1.6 \%) \mathrm{MI}, 7(0.7 \%)$ TLR and 2 $(0.2 \%)$ cases of non-target lesion target vessel revascularization. In a subset of 47 patients, 1227 cross-sections (9309 struts) were analysed at 6 months by OCT. Overall, a high percentage of struts was covered $(98.1 \%)$, with a mean neointimal thickness of $0.13 \pm 0.06 \mu \mathrm{m}$.

Conclusions: The FLEX Registry evaluated clinical outcomes in real-world and more complex cohorts and thus provides evidence that the Supraflex SEX can be used safely and routinely in a broader percutaneous coronary intervention population. Also, the Supraflex

\section{Strengths and limitations of this study}

- The major limitation of this registry is its retrospective, observational design.

- It is a non-randomised/single-arm investigation.

- At 1-year follow-up, the ultrathin $(60 \mu \mathrm{m})$ biodegradable polymer-coated sirolimus-eluting stent (SES) demonstrated a low rate of clinical events for the treatment of coronary artery disease across a wide range of unselected patients.

- By optical coherence tomography a high percentage of struts was found to be covered $(98.1 \%)$ with a mean neointimal thickness of 0.13 $\pm 0.06 \mu \mathrm{m}$ at the 6 -month follow-up.

SES showed high percentage of stent strut coverage and good stent apposition during OCT follow-up.

\section{INTRODUCTION}

The advent of drug-eluting stents (DES) radically changed the practice of percutaneous coronary intervention. Despite the remarkable efficacy of first-generation DES in reducing neointimal proliferation, and thereby lowering the need for repeat revascularisation as compared with bare-metal stents (BMS) ${ }^{1-4}$ concern about long-term safety curbed the initial enthusiasm for those devices. ${ }^{5-7}$ Several histopathological and preclinical studies with early DES identified a potential link between the occurrences of late (30 days to 1 year after stent implantation) or very late (beyond 1 year after stent 
implantation) stent thrombosis (ST) and polymermediated inflammatory reaction together with delayed healing and incomplete re-endothelialisation. ${ }^{8-11} \mathrm{~A}$ perception of increased incidence of late ST (or very late ST) with the use of durable polymer has promoted the development of DES with biodegradable polymers. In theory, biodegradable polymers afford controlled release of anti-restenotic agents and gradual degradation of the coating, which would provide the safety of BMS together with the efficacy of DES.

Also, first-generation DES were built using thick strut platforms, which have been implicated in poorer vessel response to the mechanical trauma induced by the dilatation process. ${ }^{12}$ Progressively, thinner strut stents have been developed to enhance the biocompatibility of the implant. The CE-approved Supraflex (Sahajanand Medical Technologies Pvt Ltd, Surat, India), a new biodegradable polymer-coated sirolimus-eluting stent (SES), is designed using an ultrathin $(60 \mu \mathrm{m})$ cobaltchromium $(\mathrm{Co}-\mathrm{Cr})$ stent platform with a highly flexible 'S-link', which would enhance the deliverability of the stent, particularly in complex and challenging lesions.

In this multicentre registry, we sought to evaluate clinical outcomes of an ultrathin $(60 \mu \mathrm{m})$ biodegradable polymer-coated Supraflex SES for the treatment of coronary artery disease across a wide range of 995 unselected patients treated in routine clinical practice, including those with high-risk characteristics and complex lesions. The vascular response to the Supraflex SES was also evaluated through optical coherence tomography (OCT) analysis.

\section{MATERIALS AND METHODS}

\section{Study design and patient population}

We conducted a retrospective, multicentre, single-arm, all-comers, observational registry at nine different centres in India. The registry population comprised 995 patients, with one or more stenotic lesions treated exclusively with the Supraflex SES, between July 2013 and May 2014, with no specific inclusion or exclusion criteria. A follow-up OCT analysis at 6 months was performed in a subset of 47 of these patients, who were chosen because of their access to the OCT facilities and because they gave informed consent for the analysis. The registry, design and procedures complied with the principles of good clinical practice and the Declaration of Helsinki and were approved by a local ethics committee (ethics committee, Apollo Hospitals International Ltd (Reg. No. ECR/30/Inst/GJ/2013)). All patients provided informed consent for the procedure and subsequent data collection and analysis for the research purposes.

\section{Description of the study stent}

The Supraflex SES has the Flexinnium L605 Co-Cr alloy coronary stent (Sahajanand Medical Technologies) as its stent platform. The characteristic features of the stent include its strut thickness of $60 \mu \mathrm{m}$ and highly flexible 'S-link'. Figure 1A-C shows scanning electron microscopy images of a normal, crimped and expanded Supraflex SES. These images show that the surface of the stent is coated uniformly with a thin film that conforms closely to the stent surface, the contours of the stent struts and the balloon assembly. The coating layer comprises the drug sirolimus blended together with biodegradable polymeric matrix (poly L-lactide, $50 / 50$ poly DL-lactide-co-glycolide and polyvinyl pyrrolidone) to provide programmed release of the drug. The drug, at a concentration of $1.4 \mu \mathrm{g} / \mathrm{mm}^{2}$, together with the polymeric matrix is coated on the conformal surface of the stent. The average thickness of coating ranges from 4 to $5 \mu \mathrm{m}$. The drug release occurs in two phases-about $70 \%$ of drug is released within 7 days and the remainder is released over a period of 48 days. The polymers retain their properties for a limited period and then gradually degrade into biologically acceptable molecules that are metabolised and removed from the body via normal metabolic pathways. This process takes about 912 months.

\section{Coronary intervention procedure and adjunctive drugs}

Coronary interventional procedures were carried out and adjunctive drugs used according to standard guidelines. ${ }^{13}$ All patients received dual antiplatelet therapy, including a loading dose of aspirin $(300 \mathrm{mg})$ and clopidogrel $(600 \mathrm{mg})$ or prasugrel $(60 \mathrm{mg}$ ) or ticagrelor (two tablets of $90 \mathrm{mg}$ each). Procedural anticoagulation was achieved either with heparin or bivalirudin. Intraprocedural administration of glycoprotein IIb/IIIa inhibitor was at the investigator's discretion. All patients were advised to maintain dual antiplatelet therapy
Figure 1 Scanning electron microscopy images: (A) normal stent; (B) expanded stent; (C) crimped stent.
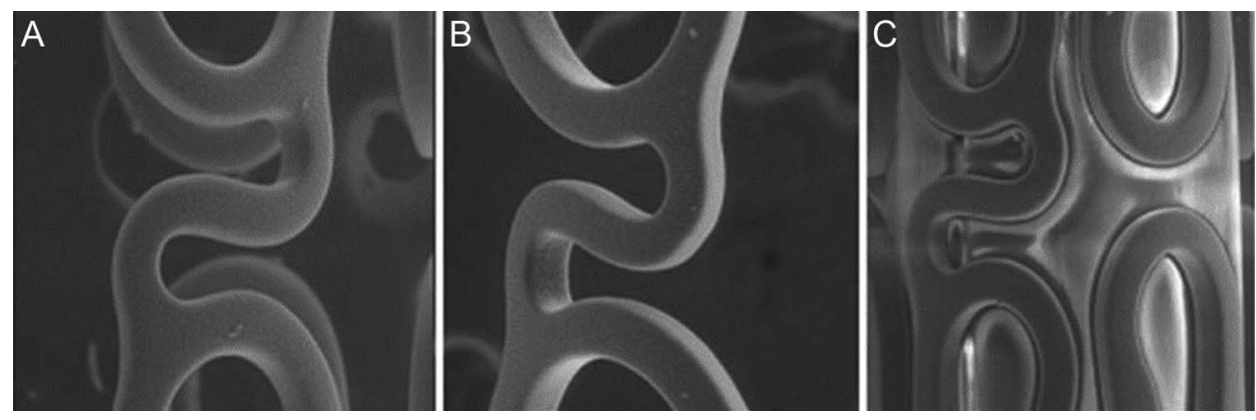
(aspirin 75-300 mg daily indefinitely and clopidogrel $75 \mathrm{mg}$ daily or prasugrel $10 \mathrm{mg}$ daily or ticagrelor $90 \mathrm{mg}$ twice daily for at least 12 months) after the procedure.

\section{Data collection and follow-up}

All data on demographic information, cardiovascular history, comorbidities, lesion and procedure characteristics and antithrombotic regimens were collected from each centre with the hospital recording network. Follow-up was obtained at 30 days, 6 and 12 months after the procedure by clinical/telephone contact with the patient and/or primary care physician and review of the electronic medical record (figure 2). During the follow-up contacts, information about patients' clinical condition, adverse events, hospitalisations and changes to concomitant (cardiac and antiplatelet) drugs were collected. All events related to endpoints were reported to an independent clinical endpoints committee, which consisted of cardiologists not taking part in the registry.

\section{Endpoints of the study and definitions}

The primary endpoint of the registry was to analyse the rate of major adverse cardiac events (MACE), defined as cardiac death, myocardial infarction (MI), target lesion revascularisation (TLR) and non-target lesion target vessel revascularisation (non-TL TVR), during 12 months' follow-up period after the index procedure. For this registry, all deaths were considered cardiac unless an unequivocal non-cardiac cause was established. MI was defined as either development of new pathological $Q$ waves in at least two contiguous leads of the electrocardiogram with or without elevated cardiac enzymes or elevation of creatine kinase greater than three times the upper limit of normal and without pathological $Q$ waves in the electrocardiogram. Re-interventions inside the implanted stent or within $5 \mathrm{~mm}$ proximally or distally to the stent were defined as TLR. Repeated percutaneous coronary intervention to the same vessel, with the exception of TLR, was counted as non-TL TVR. Repeated revascularisation in the same vessel was recorded as TVR. We also analysed the incidence of ST as a safety end point during the follow-up period. ST was defined according to the criteria of the Academic Research Consortium (ARC) ${ }^{14}$ Its timing was classified as early (within $24 \mathrm{~h}$ of the index procedure), late (occurring between 30 days to 1 year of the index procedure) or very late ST (occurring beyond 1 year of the index procedure), while its degree of certainty was classified as definite (if confirmed angiographically), probable (the patient had a target vessel-related MI or died of a coronary event) or possible (any unexplained death from 30 days after intracoronary stenting).

\section{OCT acquisition and analysis}

OCT images were obtained at the 6-month follow-up using a C7-XR Fourier-Domain system (St Jude Medical, St Paul, Minnesota, USA) at four centres where an OCT facility was available. All consecutive patients who gave consent to undergo OCT were enrolled from four centres in India. There was no preselected selection criterion. After infusion of intracoronary glyceryl trinitrate, the optical catheter was withdrawn by a motorised pullback at a constant speed of $20 \mathrm{~mm} / \mathrm{s}$, while iodixanol 320 contrast (VisipaqueTM, GE Health Care, Cork, Ireland) was infused through the guiding catheter at a continuous rate of $2-6 \mathrm{~mL} / \mathrm{s}$. All OCT images were analysed at an independent core laboratory (Heart Institute (InCor), São Paulo, Brazil) by analysts who were blinded to patient and procedural information, using validated software (QIvus V.3.0; Medis, Leiden, the Netherlands). Cross-sectional OCT images were analysed at $1 \mathrm{~mm}$ intervals. Stent and luminal cross-sectional areas (CSAs) were measured, and the neointimal cross-sectional area was calculated as the stent CSA minus the luminal CSA. The stent volume (SV), lumen volume (LV) and neointimal volume $(\mathrm{NV}=\mathrm{SV}-\mathrm{LV})$ were also computed. The percentage of in-stent neointimal volume obstruction $(\% \mathrm{NVO})$ was calculated as $\mathrm{NV} / \mathrm{SV} \times 100 \%$. Neointimal thickness was defined as the distance between the endoluminal surface of the neointima and the luminal surface of the strut reflection at the mid-point of the

Figure 2 Study flow chart. 
strut and on a line perpendicular to the neointima and strut. A covered strut was defined as having neointimal thickness more than $0 \mu \mathrm{m}$. The percentage of covered struts was calculated as the number of covered struts $\times 100$ divided by the number of total struts which were analysable. Incomplete strut apposition was defined as a clear separation between strut and vessel wall with a distance greater than the thickness of the strut. ${ }^{15}$

In addition, the healing index to quantify the degree of vessel healing was calculated. This score combines the following parameters: (a) presence of intraluminal defect (intraluminal defect area both free from the wall and attached to the lumen/stent area) is assigned a weighting factor of 4; (b) presence of both malapposed and uncovered struts is assigned a weighting factor of 3 ; (c) presence of uncovered struts alone is assigned a weighting factor of 2; (d) presence of malapposition alone is assigned a weighting factor of 1 and (e) presence of neointimal volume obstruction of $>30 \%$ will be calculated by \% NVO minus 30 then assigned a weighting factor of 1 (if the neointimal volume was $<30 \%$, this factor was omitted). ${ }^{16}$

\section{Statistical analysis}

Data are presented using descriptive statistical methods. Continuous variables are presented as mean \pm SD, whereas categorical variables are expressed as percentages. All data were processed using the Statistical Package for Social Sciences, V.15 (SPSS, Chicago, Illinois, USA).

\section{RESULTS}

\section{Baseline, lesion and procedural characteristics}

A total of 995 patients, with mean $\pm \mathrm{SD}$ age $61.6 \pm 10.8$ years, were evaluated in this registry. Among the included patients, 441(44.3\%) were hypertensive and 231 (23.2\%) were diabetic. Other important baseline clinical characteristics of the registry population are outlined in table 1 . Details of lesion and procedural characteristics are listed in table 2. In brief, approximately half of all lesions $(\mathrm{n}=580 ; 46.7 \%)$ were located in the left anterior descending artery, while most lesions were of type B2/C ( $\mathrm{n}=969$; $78.0 \%)$. A total of 1398 stents were implanted (1.4 \pm 0.7 stents per patient) to treat 1242 lesions.

\section{Clinical outcomes}

Follow-up was available in $98.5 \%(980 / 995)$ of patients at the end of 12 months and cumulative rates of MACE are depicted in table 3. MACE rates while in hospital, at 30 days and at 6 months were $0.4 \%$ (4/995), $1.1 \%$ (11/ 995) and 2.2\% (22/986), respectively. At 12 months, the primary endpoint occurred in $36(3.7 \%)$ of 980 patients, consisting of $18(1.8 \%)$ cardiac deaths, $16(1.6 \%)$ MI, 7 $(0.7 \%)$ TLR and $2(0.2 \%)$ non-TL TVR. Of these 18 cardiac deaths, four deaths were reported in hospital in patients undergoing primary angioplasty for acute MI, three deaths occurred after discharge owing to severe

\begin{tabular}{lc}
$\begin{array}{l}\text { Table } 1 \text { Baseline clinical characteristics of patients in the } \\
\text { registry population }\end{array}$ \\
\hline Variables & Patients ( $\mathrm{n=995)}$ \\
\hline Demographic & \\
Age (years), (mean \pm SD) & $61.6 \pm 10.8$ \\
Male, $\mathrm{n}(\%)$ & $796(80.0)$ \\
Coexisting condition & $231(23.2)$ \\
Diabetes mellitus, $\mathrm{n}(\%)$ & $441(44.3)$ \\
Hypertension, $\mathrm{n}(\%)$ & $398(40)$ \\
ACS, $\mathrm{n}(\%)$ & $71(7.1)$ \\
Cardiac risk factor & $79(7.9)$ \\
Current smoker, $\mathrm{n}(\%)$ & $3(0.3)$ \\
Family history of CAD, $\mathrm{n}(\%)$ & $109(11.0)$ \\
Previous stroke, $\mathrm{n}(\%)$ & $15(1.5)$ \\
$\quad$ Previous MI, $\mathrm{n}(\%)$ & $87(8.7)$ \\
$\quad$ Previous CABG, $\mathrm{n}(\%)$ & $363(36.5)$ \\
$\quad$ Previous PCI, $\mathrm{n}(\%)$ & $381(38.3)$ \\
Severity of disease & $251(25.2)$ \\
Single vessel disease, $\mathrm{n}(\%)$ & \\
Double vessel disease, $\mathrm{n}(\%)$ & \\
Triple vessel disease, $\mathrm{n}(\%)$ & \\
\hline ACS, acute coronary syndrome; CABG, coronary artery bypass \\
grafting; CAD, coronary artery disease; MI, myocardial infarction; \\
PCl, percutaneous coronary intervention.
\end{tabular}

left ventricular dysfunction, while other patients died at home after a period of 30 days (table 3). According to the ARC definition, definite and probable ST occurred in $1.1 \%(11 / 980)$ of patients through 12 months. Cumulative MACE-free survival, at 12 months' follow-up, determined by the Kaplan-Meier method, was $96.3 \%$ as shown in figure 3 .

\section{OCT outcomes}

OCT analyses were performed on three levels: the lesion level, the cross-sectional level, and the struts level. By OCT, in a subset of 47 patients, 1227 cross-sections (9309 struts) were analysed at 6 months and the data are shown in table 4 . In brief, a high percentage of struts was covered $(98.1 \%)$, with a mean neointimal thickness of $0.13 \pm 0.06 \mu \mathrm{m}$. Figure $4 \mathrm{~A}$ shows the cumulative frequency of the percentage of covered struts and figure $4 \mathrm{~B}$ presents the distribution of neointimal thickness in all lesions.

\section{DISCUSSION}

For many years, stents used $316 \mathrm{~L}$ stainless steel, owing to its excellent combination of mechanical properties, corrosion resistance and biocompatibility. Reduction of strut thickness from (130-140 $\mu \mathrm{m})$ further improved flexibility and trackability, while maintaining radial strength and minimal recoil, leading to improved stent deliverability and reduced restenosis rates. ${ }^{17}$ It has also been proved that thick strut stents are more thrombogenic than identical thin-strut stents in ex vivo and in vivo models. ${ }^{18}$ Hence, newer DES were developed with biodegradable polymers and thinner struts to improve 
Table 2 Lesion and procedural characteristics

\begin{tabular}{|c|c|}
\hline Variables & $\begin{array}{l}\text { Patients }(n=995) / \\
\text { lesions }(n=1242)\end{array}$ \\
\hline \multicolumn{2}{|l|}{ Target vessel location } \\
\hline Left main artery, $\mathrm{n}(\%)$ & $11(0.9)$ \\
\hline $\begin{array}{l}\text { Left anterior descending artery, } \\
\mathrm{n}(\%)\end{array}$ & $580(46.7)$ \\
\hline Right coronary artery, n (\%) & $364(29.3)$ \\
\hline Left circumflex artery, n (\%) & $286(23.0)$ \\
\hline Saphenous vein graft, $n(\%)$ & $1(0.1)$ \\
\hline \multicolumn{2}{|c|}{ Lesion classification (ACC/AHA score) } \\
\hline Type A, n (\%) & $76(6.1)$ \\
\hline Type B1, n (\%) & $197(15.9)$ \\
\hline Type B2, n (\%) & $258(20.8)$ \\
\hline Type C, n (\%) & $711(57.2)$ \\
\hline Total no. of stents, $n$ & 1398 \\
\hline No. of stents per patient, (mean $\pm S D$ ) & $1.4 \pm 0.7$ \\
\hline No. of stents per lesion, (mean $\pm S D)$ & $1.1 \pm 0.4$ \\
\hline $\begin{array}{l}\text { Average stent length }(\mathrm{mm}) \text {, (mean } \\
\pm \mathrm{SD} \text { ) }\end{array}$ & $26.6 \pm 9.3$ \\
\hline $\begin{array}{l}\text { Average stent diameter }(\mathrm{mm}) \text {, } \\
(\text { mean } \pm \mathrm{SD})\end{array}$ & $3.1 \pm 0.4$ \\
\hline Total occlusion, n (\%) & $185(14.9)$ \\
\hline Chronic total occlusion, n (\%) & $113(9.1)$ \\
\hline Stent size description & $\begin{array}{l}\text { Total no. of stents } \\
n=1398\end{array}$ \\
\hline \multicolumn{2}{|l|}{ Stent length (mm) } \\
\hline 8 & $2(0.1)$ \\
\hline 12 & $103(7.4)$ \\
\hline 16 & $212(15.2)$ \\
\hline 20 & $225(16.1)$ \\
\hline 24 & $178(12.7)$ \\
\hline 28 & $151(10.8)$ \\
\hline 32 & $145(10.4)$ \\
\hline 36 & $95(6.8)$ \\
\hline 40 & $287(20.5)$ \\
\hline \multicolumn{2}{|l|}{ Stent diameter (mm) } \\
\hline 2.00 & $3(0.2)$ \\
\hline 2.25 & $9(0.6)$ \\
\hline 2.50 & $191(13.7)$ \\
\hline 2.75 & $247(17.7)$ \\
\hline 3.00 & 469 (33.5) \\
\hline 3.50 & $422(30.2)$ \\
\hline 4.00 & $57(4.1)$ \\
\hline
\end{tabular}

the clinical outcomes, even in complex lesions. ${ }^{19-21}$ The clinical outcomes of the ISAR-3 trial also favour biodegradable polymer-coated DES rather than permanent polymer-coated DES. $^{22}$ Recently, pooled analysis of large multicentre randomised trials also showed a lower risk of TVR and very late ST associated with biodegradable polymers compared with durable polymer-coated DES. ${ }^{23}$

The Supraflex, a new sirolimus-eluting coronary stent, incorporates biodegradable polymeric matrix for the sustained release of active pharmaceutical ingredients.
Once its useful function is served, the polymers gradually degrade into biologically acceptable molecules that are metabolised and removed from the body via normal metabolic pathways, avoiding inflammatory reactions. So, the biodegradable polymer-coated DES offer antirestenotic benefits and once the polymers have biodegraded, it offers the safety benefits of BMS. In addition to biodegradable polymers, the Supraflex SES has a thinner Co-Cr-based strut $(60 \mu \mathrm{m})$ than other available biodegradable SES. The Supralimus-Core (Sahajanand Medical Technologies) is a clinically proven sirolimus-eluting coronary stent and its safety and efficacy has demonstrated in real-life patients. ${ }^{24} 25$ The Supraflex SES is a further improved version of the Supralimus-Core SES with replacement of the rigid interlink/joint of the Supralimus-Core SES with a highly flexible 'S-link', which increases flexibility and deliverability of the Supraflex SES. Additionally, in the S-CORE Registry (multicentre registry of Supralimus-Core biodegradable polymer SES), which enrolled 562 'realworld' patients, the incidence of MACE at 30 days and 6 months was $7(1.2 \%)$ and $12(2.1 \%)$, respectively. Furthermore, the composite rate of MACE at a 12-month clinical follow-up was $19(3.4 \%)$, consisting of $12(2.1 \%)$ cardiac deaths, $0(0 \%)$ MI, 6 (1.1\%) TLR and $1(0.2 \%)$ TVR. Findings of this S-CORE Registry showed satisfactory safety and efficacy for the Co-Cr biodegradable polymer-based sirolimus-eluting Supralimus-Core stent in a 'real-world' setting as seen from low rates of MACE up to 12 months. ${ }^{25}$

Usually, randomised controlled trials or first-in-man studies enrol a low-risk population (clinically stable or straightforward lesions), and thus results of such studies cannot be extrapolated to 'real-world' patients with higher risk or with complex coronary anatomy. Accurate post-market surveillance may provide valuable data of a more real population treated in a true clinical setting. Therefore, we designed this retrospective multicentre registry to evaluate clinical outcomes of the Supraflex SES in 'all-comer' unselected Indian patients treated in routine clinical practice. The most salient feature of this registry was that all consecutive patients from each centre during the specified period were included and follow-up was available for $980(98.5 \%)$ patients at 12 months. Although randomised trials are considered as the highest level of evidence, they have many problems. Apart from the higher costs, it is difficult to conduct a randomised trial against a single particular stent which can be considered as the only benchmark. DES are in a constant state of evolution and the benchmark keeps changing, so a well-conducted registry with excellent follow-up may help to compare the study stent with multiple benchmarks.

In our registry, characteristic of current practice, $44.3 \%$ of the patients had hypertension, $23.2 \%$ had diabetes and a significant percentage of patients had type B2/C lesions $(78.0 \%)$ and total occlusion (14.9\%), of which chronic total occlusion was present in $9.1 \%$ 
Table 3 Cumulative rates of MACE

\begin{tabular}{|c|c|c|c|}
\hline Variables & 30 Days & 6 Months & 12 Months \\
\hline No. of patients, $n$ & 995 & 986 & 980 \\
\hline Death, n (\%) & $7(0.7)$ & $10(1.0)$ & $22(2.2)$ \\
\hline Cardiac death, n (\%) & $7(0.7)$ & $9(0.9)$ & $18(1.8)$ \\
\hline Non-cardiac death, n (\%) & $0(0)$ & $1(0.1)$ & $4(0.4)$ \\
\hline $\mathrm{MI}, \mathrm{n}(\%)$ & $4(0.4)$ & $15(1.5)$ & $16(1.6)$ \\
\hline TLR, n (\%) & $0(0)$ & $5(0.5)$ & $7(0.7)$ \\
\hline Non-TL TVR, n (\%) & $0(0)$ & $0(0)$ & $2(0.2)$ \\
\hline Overall stent thrombosis, n (\%) & $0(0)$ & $11(1.1)$ & $11(1.1)$ \\
\hline Definite stent thrombosis, $\mathrm{n}(\%)$ & $0(0)$ & $3(0.3)$ & $3(0.3)$ \\
\hline Probable stent thrombosis, $\mathrm{n}(\%)$ & $0(0)$ & $8(0.8)$ & $8(0.8)$ \\
\hline Possible stent thrombosis, n (\%) & $0(0)$ & $0(0)$ & $0(0)$ \\
\hline MACE, $n(\%)$ & $11(1.1)$ & $22(2.2)$ & $36(3.7)$ \\
\hline
\end{tabular}

patients and the remaining 5.8\% patients had acute coronary syndrome with total occlusion. Despite the complexity of the present patient population, a lower MACE rate $(3.7 \%)$ and TLR incidence $(0.7 \%)$ at 12 months' follow-up showed favourable clinical outcomes of the Supraflex SES. The lower incidence of TLR is comparable with that reported for other biodegradable polymer-coated, newer-generation, thin-strut DES. The CENTURY study, a first-in-man experience of the Ultimaster coronary stent (Terumo Corp, Tokyo, Japan), is a thin-strut, Co-Cr, bioresorbable polymer-coated SES, which reported $1.0 \%$ (1 incidence in 105 patients) clinically driven TLR in patients with de novo lesions (in up to two native coronary arteries).$^{20}$ In the EVOLVE trial, the incidence of TLR was found to be $1.1 \%$ in 94 patients treated with the Synergy stent for de novo artherosclerotic lesions. ${ }^{26}$ However, longer follow-up of patients receiving the Supraflex SES will be necessary to confirm long-term safety of this DES and this is being undertaken.

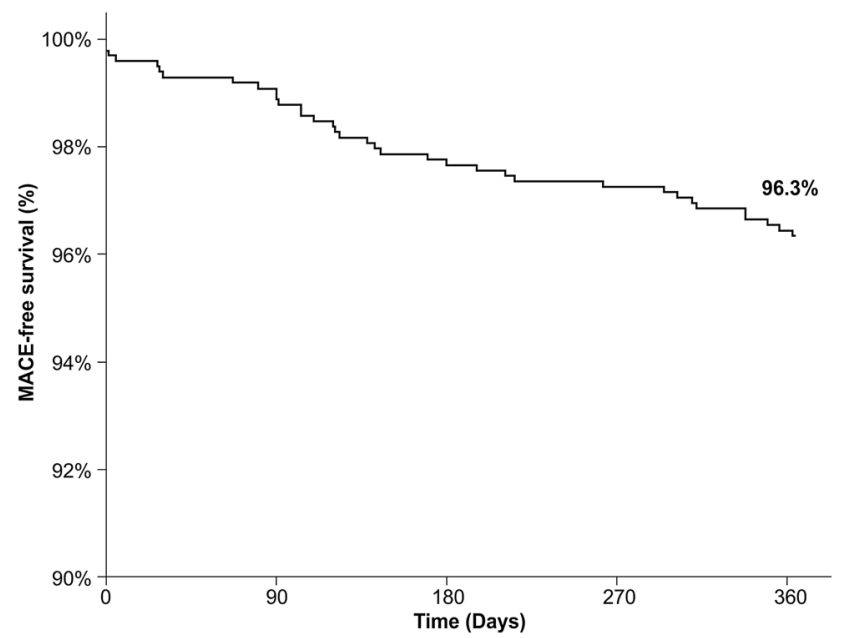

Figure 3 Kaplan-Meier major adverse cardiac events (MACE)-free survival curve through 12 months.
Furthermore, the risk of late ST remains a major concern where its incidence is dependent on a lack of strut coverage. ${ }^{27}$ Therefore, assessment of covered struts by imaging modalities at follow-up is considered to be an important surrogate to help stratify the patient's future risk for thrombotic events. In our registry, OCT analysis of the Supraflex SES showed $98.1 \%$ strut

Table 4 Optical coherence tomography analysis at 6-month follow-up

\begin{tabular}{|c|c|}
\hline \multicolumn{2}{|l|}{ Strut level analysis } \\
\hline Total analysed struts, $\mathrm{n}$ & 9309 \\
\hline $\begin{array}{l}\text { Number of struts per cross-section, } \\
\text { mean } \pm S D\end{array}$ & $7.58 \pm 0.87$ \\
\hline Percentage of covered struts & $98.1(92.1-100)$ \\
\hline Neointimal thickness $(\mu \mathrm{m})$, mean $\pm S D$ & $0.13 \pm 0.06$ \\
\hline Percentage of malapposed struts & $0.00(0.00-4.1)$ \\
\hline Percentage presence of both & $2.40(0.00-10.1)$ \\
\hline \multicolumn{2}{|l|}{ malapposed or uncovered struts } \\
\hline \multicolumn{2}{|l|}{ Cross-section-level analysis } \\
\hline Total analysed cross-sections, $\mathrm{n}$ & 1227 \\
\hline $\begin{array}{l}\text { Minimum lumen area }\left(\mathrm{mm}^{2}\right) \text {, } \\
\text { mean } \pm S D\end{array}$ & $4.25 \pm 1.83$ \\
\hline Lumen area $\left(\mathrm{mm}^{2}\right)$, mean $\pm \mathrm{SD}$ & $5.71 \pm 1.90$ \\
\hline $\begin{array}{l}\text { Minimum stent area }\left(\mathrm{mm}^{2}\right) \\
\text { mean } \pm \text { SD }\end{array}$ & $5.57 \pm 1.69$ \\
\hline Stent area $\left(\mathrm{mm}^{2}\right)$, mean \pm SD & $6.96 \pm 1.99$ \\
\hline Neointimal area $\left(\mathrm{mm}^{2}\right)$, mean \pm SD & $1.25 \pm 0.61$ \\
\hline Mean ISA area $\left(\mathrm{mm}^{2}\right)$ & $0.00(0.00-0.00)$ \\
\hline \multicolumn{2}{|l|}{ Lesion-level analysis } \\
\hline Total analysed lesions, $n$ & 47 \\
\hline Mean area of ISA $>2 \mathrm{~mm}^{2}, \mathrm{n}(\%)$ & 0 \\
\hline Thrombus area $>300 \mu m^{2}, n(\%)$ & 0 \\
\hline Neointima volume, $\mathrm{mm}^{3}$ & $30.6(19.1-40.7)$ \\
\hline Stent volume $\left(\mathrm{mm}^{3}\right)$, mean $\pm S D$ & $184.2 \pm 78.2$ \\
\hline Lumen volume $\left(\mathrm{mm}^{3}\right)$, mean $\pm S D$ & $151.2 \pm 69.9$ \\
\hline $\begin{array}{l}\text { Percentage of neointima volume } \\
\text { obstruction }\end{array}$ & $17.6 \pm 9.5$ \\
\hline Healing index (no unit) & $4.8(1.0-22.9)$ \\
\hline
\end{tabular}




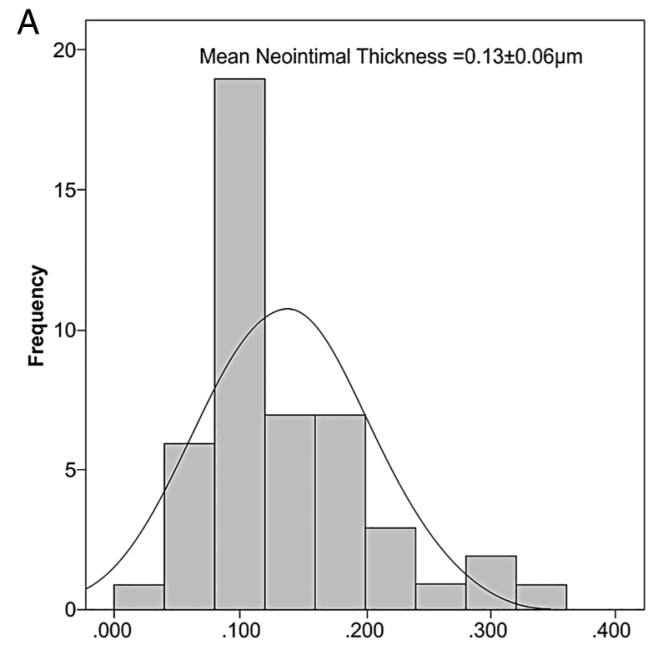

B

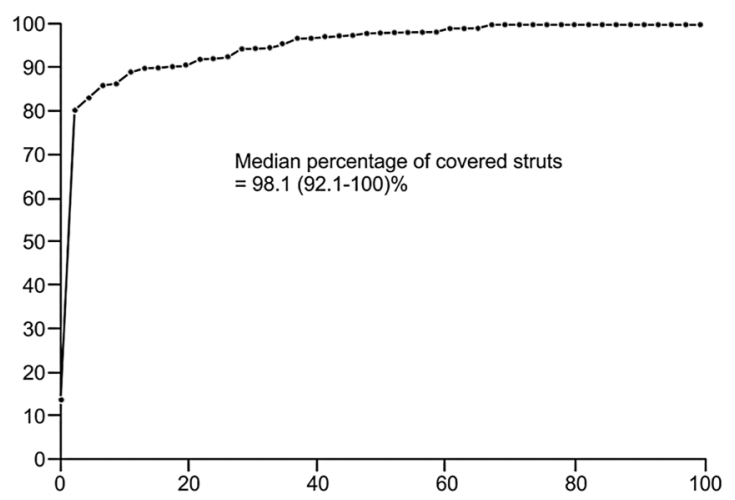

Figure 4 Cumulative frequency curve of percentage of covered struts (A) and histogram of neointimal thickness (B).

coverage at 6 months, while it was $91.5 \%$ and $94.1 \%$ in the PROMUS Element and XIENCE DES, respectively. ${ }^{28}$

The Supraflex SES had a favourable healing index of 4.8 (1.0-22.9). Lack of healing and absence of endothelial cell coverage of the stent struts have been strongly associated with DES late thrombosis in human autopsy studies. ${ }^{29}$ The healing index combines multiple factors (coverage, malapposition, exuberant neointimal proliferation and intraluminal defect). By OCT, patients with late thrombosis-compared with control subjects- had a higher percentage of uncovered (median (IQR)) (12.27 (5.50-23.33) vs $4.14(3.00-6.22), \mathrm{p}<0.001)$ and malapposed $(4.60 \quad(1.85-7.19) \quad$ vs $1.81 \quad(0.00-2.99)$, $\mathrm{p}<0.001)$ struts. Consequently, the most influential factors of the healing index are the percentage of uncovered struts and number of cases of incomplete stent apposition: both are low in our study. In comparison, the healing index of the biolimus A9-eluting BioMatrix stent was found to be $35.2 \pm 25.0$, of the sirolimus-eluting Cypher stent with durable polymer $43.3 \pm 36.2$, of the zotarolimus-eluting Resolute stent $18.7 \pm 20.4$ and of the everolimus-eluting Xience stents $10.8 \pm 15.3 .^{30} 31$

\section{Study limitations}

The major limitation of this registry is its retrospective, observational design. It also has the disadvantage of being a non-randomised/single-arm investigation. In addition, the follow-up time of 12 months was relatively short and might have led to underestimation of the benefits of the study stent. Long-term follow up is necessary to assess the true event rates.

\section{CONCLUSIONS}

The results of the FLEX Registry provide evidence for the safe and effective use of the Supraflex SES in realworld, all-comers patients, including those with high clinical and anatomical complexity, with low event rates at 12 months' follow-up during unrestricted daily practice. Also, the Supraflex SES showed a high percentage of stent strut coverage and good stent apposition during OCT follow-up.

Author affiliations

${ }^{1}$ Heart Institute (InCor), University of Sao Paulo Medical School, Sao Paulo, Brazil

${ }^{2}$ Heart and General Hospital, Jaipur, Rajasthan, India

${ }^{3}$ Max Superspeciality Hospital, Mohali, Punjab, India

${ }^{4}$ Kasturba Medical College and Hospital, Manipal, Karnataka, India

${ }^{5}$ Shree B D Mehta Mahavir Heart Institute, Surat, Gujarat, India

${ }^{6} \mathrm{ACE}$ Heart and Vascular Institute, Mohali, Punjab, India

${ }^{7}$ Artemis Hospital, Gurgaon, Haryana, India

${ }^{8}$ Soni Manipal Hospital, Jaipur, Rajasthan, India

${ }^{9}$ Apple Hospitals and Research Institute, Kolhapur, Maharashtra, India

${ }^{10}$ Apollo Hospitals International Limited, Gandhinagar, Gujarat, India

Contributors PAL: drafted the manuscript and supervised optical coherence tomography (OCT) analysis. CMC: drafted the manuscript and performed OCT analysis. JFM, MZG: performed OCT analysis. PC, SS, PKR, AA, PV, MSS, NP, SJ, JP: enrolled patients and reviewed the manuscript. $A B$ : drafted and reviewed the manuscript.

Funding Supported by Sahajanand Medical Technologies, Surat, India.

Competing interests AA receives consultant fees from Sahajanand Medical Technologies, Surat, India.

Patient consent Obtained.

Ethics approval Local ethics committee/institutional review board (at each institution).

Provenance and peer review Not commissioned; externally peer reviewed.

Data sharing statement No additional data are available.

Open Access This is an Open Access article distributed in accordance with the Creative Commons Attribution Non Commercial (CC BY-NC 4.0) license, which permits others to distribute, remix, adapt, build upon this work noncommercially, and license their derivative works on different terms, provided the original work is properly cited and the use is non-commercial. See: http:// creativecommons.org/licenses/by-nc/4.0/

\section{REFERENCES}

1. Colombo A, Drzewiecki J, Banning A, et al. Randomized study to assess the effectiveness of slow- and moderate-release polymer-based paclitaxel-eluting stents for coronary artery lesions. Circulation 2003;108:788-94. 
2. Moses JW, Leon MB, Popma JJ, et al. Sirolimus-eluting stents versus standard stents in patients with stenosis in a native coronary artery. N Engl J Med 2003;349:1315-23.

3. Sousa JE, Costa MA, Abizaid A, et al. Four-year angiographic and intravascular ultrasound follow-up of patients treated with sirolimus-eluting stents. Circulation 2005;111:2326-9.

4. Stone GW, Ellis SG, Cox DA, et al. A polymer-based, paclitaxel-eluting stent in patients with coronary artery disease. N Engl J Med 2004;350:221-31.

5. Beohar N, Davidson CJ, Kip KE, et al. Outcomes and complications associated with off-label and untested use of drug-eluting stents. JAMA 2007;297:1992-2000.

6. Feres F, Costa JR Jr, Abizaid A. Very late thrombosis after drug-eluting stents. Catheter Cardiovasc Interv 2006;68:83-8.

7. Lagerqvist B, James SK, Stenestrand U, et al. Long-term outcomes with drug-eluting stents versus bare-metal stents in Sweden. $N$ Engl J Med 2007;356:1009-19.

8. Joner M, Finn AV, Farb A, et al. Pathology of drug-eluting stents in humans: delayed healing and late thrombotic risk. J Am Coll Cardiol 2006;48:193-202.

9. Pfisterer ME. Late stent thrombosis after drug-eluting stent implantation for acute myocardial infarction: a new red flag is raised. Circulation 2008:118:1117-19.

10. Virmani R, Guagliumi G, Farb A, et al. Localized hypersensitivity and late coronary thrombosis secondary to a sirolimus-eluting stent: should we be cautious? Circulation 2004;109:701-5.

11. Nebeker JR, Virmani R, Bennett CL, et al. Hypersensitivity cases associated with drug-eluting coronary stents: a review of available cases from the Research on Adverse Drug Events and Reports (RADAR) project. J Am Coll Cardiol 2006;47:175-81.

12. Navarese EP, Kowalewski M, Kandzari D, et al. First-generation versus second-generation drug-eluting stents in current clinical practice: updated evidence from a comprehensive meta-analysis of randomised clinical trials comprising 31379 patients. Open Heart 2014;1:e000064

13. King SB III, Smith SC Jr, Hirshfeld JW Jr, et al. 2007 Focused Update of the ACC/AHA/SCAI 2005 Guideline Update for Percutaneous Coronary Intervention: a report of the American College of Cardiology/American Heart Association Task Force on Practice Guidelines: 2007 Writing Group to Review New Evidence and Update the ACC/AHA/SCAI 2005 Guideline Update for Percutaneous Coronary Intervention, Writing on Behalf of the 2005 Writing Committee. Circulation 2008;117:261-95

14. Cutlip DE, Windecker S, Mehran R, et al. Clinical end points in coronary stent trials: a case for standardized definitions. Circulation 2007;115:2344-51.

15. Gonzalo N, Garcia-Garcia HM, Serruys PW, et al. Reproducibility of quantitative optical coherence tomography for stent analysis. Eurolntervention 2009;5:224-32.

16. García-García HM, Muramatsu T, Nakatani S, et al. Serial optical frequency domain imaging in STEMI patients: the follow-up report of TROFI study. Eur Heart J Cardiovasc Imaging 2014;15:987-95.

17. Kastrati A, Mehilli J, Dirschinger J, et al. Intracoronary stenting and angiographic results: strut thickness effect on restenosis outcome (ISAR-STEREO) trial. Circulation 2001;103:2816-21.

18. Kolandaivelu K, Swaminathan R, Gibson WJ, et al. Stent thrombogenicity early in high-risk interventional settings is driven by stent design and deployment and protected by polymer-drug coatings. Circulation 2011;123:1400-9.

19. Ribeiro EE, Campos CM, Ribeiro HB, et al. First-in-man randomised comparison of a novel sirolimus-eluting stent with abluminal biodegradable polymer and thin-strut cobalt-chromium alloy: INSPIRON-I trial. Eurolntervention 2014;9:1380-4.

20. Barbato E, Salinger-Martinovic S, Sagic D, et al. A first-in-man clinical evaluation of Ultimaster, a new drug-eluting coronary stent system: CENTURY study. Eurolntervention 2015;11: 541-8.

21. Pilgrim $T$, Heg D, Roffi $M$, et al. Ultrathin strut biodegradable polyme sirolimus-eluting stent versus durable polymer everolimus-eluting stent for percutaneous coronary revascularisation (BIOSCIENCE): a randomised, single-blind, non-inferiority trial. Lancet 2014;384:2111-22.

22. Mehilli J, Byrne RA, Wieczorek A, et al. Randomized trial of three rapamycin-eluting stents with different coating strategies for the reduction of coronary restenosis. Eur Heart $J$ 2008;29: 1975-82.

23. Stefanini GG, Byrne RA, Serruys PW, et al. Biodegradable polymer drug-eluting stents reduce the risk of stent thrombosis at 4 years in patients undergoing percutaneous coronary intervention: a pooled analysis of individual patient data from the ISAR-TEST 3 ,

ISAR-TEST 4, and LEADERS randomized trials. Eur Heart $J$ 2012;33:1214-22.

24. Seth A, Chandra P, Chouhan NS, et al. A first-in-man study of sirolimus-eluting, biodegradable polymer coated cobalt chromium stent in real life patients. Indian Heart $J$ 2012;64: 547-52.

25. Chandwani $P$, Abhyankar AD, Prajapati J, et al. Clinical performance of the cobalt-chromium biodegradable polymer coated sirolimus-eluting stent in an unselected real-world population. Int $J$ Clin Med 2014;5:206-15.

26. Meredith IT, Verheye S, Dubois CL, et al. Primary endpoint results of the EVOLVE trial: a randomized evaluation of a novel bioabsorbable polymer-coated, everolimus-eluting coronary stent. J Am Coll Cardiol 2012:59:1362-70.

27. Finn AV, Joner M, Nakazawa G, et al. Pathological correlates of late drug-eluting stent thrombosis: strut coverage as a marker of endothelialization. Circulation 2007;115:2435-41.

28. Guagliumi G, Capodanno D, Ikejima $\mathrm{H}$, et al. Impact of different stent alloys on human vascular response to everolimus-eluting stent: an optical coherence tomography study: the OCTEVEREST. Catheter Cardiovasc Interv 2013;81:510-18.

29. Finn AV, Nakazawa G, Joner M, et al. Vascular responses to drug eluting stents: importance of delayed healing. Arterioscler Thromb Vasc Biol 2007;27:1500-10.

30. Gutiérrez-Chico JL, van Geuns RJ, Regar E, et al. Tissue coverage of a hydrophilic polymer-coated zotarolimus-eluting stent vs. a fluoropolymer-coated everolimus-eluting stent at 13-month follow-up: an optical coherence tomography substudy from the RESOLUTE All Comers trial. Eur Heart J 2011;32:2454-63.

31. Gutiérrez-Chico JL, Gijsen F, Regar E, et al. Differences in neointimal thickness between the adluminal and the abluminal sides of malapposed and side-branch struts in a polylactide bioresorbable scaffold: evidence in vivo about the abluminal healing process. JACC Cardiovasc Interv 2012;5:428-35. 